\title{
Commentary on Plasma Levels of Homovanillic Acid (phVA) under Influence of Mental Stress
}

Sumiyoshi et al. $(1998,1999)$ propose that plasma levels of homovanillic acid (pHVA) change under influence of mental stress. In the first study they compared pHVA levels before and after a stress test in healthy controls. In the second study, they compared pHVA levels before and after a stress test in schizophrenic patients and healthy controls. The methods of both studies are the same: pre-test blood sampling was performed through an intravenous line at 9.00 A.M., immediately followed by a modified version of Kraepelin's arithmetic test as a stressor (a test of continuous arithmetic addition for 30 minutes), followed by post-test blood sampling. The study design did not include a "placebo" condition because the authors found it unlikely that significant changes in pHVA would occur in only 30 minutes in the absence of stress (Sumiyoshi et al. 1998). They found reduced pHVA in the posttest blood sample when compared to the pre-test sample and concluded that this was a direct effect of the stresstest. However, we propose an alternative explanation for these results: the reduction of the pHVA might be the result of its endogenous diurnal variation.

In our department, healthy male volunteers participated in a study with similar methodological design to that of Sumiyoshi et al. $(1998,1999)$ : the subjects were required to fast from 11:00 P.M. the night before testing through the conclusion of testing the following day. On the test day, an intravenous catheter for blood sampling was inserted at 8:30 A.M. after which the subjects participated in a battery of four psychophysiological tasks, beginning at 11:00 A.M. During the test day, seven blood samples were taken (8:45, 9:30, 10:30, 11:30, 11:55, 12:30, and 13:30). We found a significant decrease in pHVA level through the course of the day $(\mathrm{t} 1=8.48 \mathrm{ng} / \mathrm{ml}, \mathrm{t} 2=6.91 \mathrm{ng} / \mathrm{ml}, \mathrm{t} 3=6.09 \mathrm{ng} / \mathrm{ml}, \mathrm{t} 4=$ $6.11 \mathrm{ng} / \mathrm{ml}, \mathrm{t} 5=6.05 \mathrm{ng} / \mathrm{ml}, \mathrm{t} 6=5.65 \mathrm{ng} / \mathrm{ml}, \mathrm{t} 7=5.41$ $\mathrm{ng} / \mathrm{ml} ; \mathrm{F}(90,6)=22.89, p<.001)$. Further analysis showed significant decreases between the measurements at 8.45 and $9.30(t=4.96 ; p<.0001)$. The only methodological difference between the first hour of our study and that of Sumiyoshi et al. $(1998,1999)$ is the absence of a stressor between the two blood samples drawn. Therefore, the drop in pHVA in the studies of Sumiyoshi et al. $(1998,1999)$ might be explained as the natural variation of this metabolite during the day. Further evidence for a naturally occurring endogenous diurnal rhythm is found in the study of Doran et al. (1985); they found a diurnal variation in pHVA with a peak during early morning and a dip in early afternoon. Furthermore, Davidson and Davis (1988) measured pHVA in schizophrenic patients and healthy controls and found a similar diurnal variation of pHVA in healthy subjects (i.e., a rise during early morning hours followed by a subsequent decrease). In addition, Stroe et al. (1997) found a significant decline in pHVA over time in healthy volunteers from 9:00 A.M. to 10:30 A.M.

In conclusion, in future studies assessing the effects of stress on pHVA, a placebo condition without stressor must be included to control for diurnal variation or other possible confounding variables.

Bob Oranje, M.A.
Suzanne Bijl, M.A.
Antonet Campagne, M.A.
Christine C. Gispen-de Wied, M.D., Ph.D.
Department of Psychiatry
University Medical Centre
Utrecht, The Netherlands

\section{REFERENCES}

Davidson M, Davis KL (1988): A comparison of plasma homovanillic acid concentrations in schizophrenic 
patients and normal controls. Arch Gen Psychiatry 45:561-563

Doran AR, Pickar D, Labarca R, Douillet P, Wolkowitz OM, Thomas JW, Roy A, Paul SM (1985): Evidence for a daily rhythm of plasma HVA in normal controls but not in schizophrenic patients. Psychopharmacol Bull 21:694697

Stroe AE, Amin F, Hashmi A, Densmore D, Kahn T, Knott PJ (1997): Diurnal variation in plasma homovanillic acid: Not a renal phenomenon. Biol Psychiatry 41:621623

Sumiyoshi T, Yotsutsuii T, Kurachi M, Itoh H, Kurokawa K, Saitoh O (1998): Effect of mental stress on plasma homovanillic acid in healthy human subjects. Neuropsychopharmacology 19:70-73

Sumiyoshi T, Saitoh O, Yotsutsuji T, Itoh H, Kurokawa K, Kurachi M (1999): Differential effects of mental stress on plasma homovanillic acid in schizophrenia and normal controls. Neuropsychopharmacology 20:365-369 